\title{
Plasticity and Conservation
}

\author{
Ulrich Lüttge
}

\author{
Institut fuer Botanik, Technische Universitaet Darmstadt, Darmstadt, Germany
}

\begin{abstract}
Plasticity is a feature of phenotypes and genotypes. Genetic variation is reflected in phenotypic plasticity. When conservation protects genomes it protects complexity and with complexity it protects the beauty of life. However, plasticity is not to be considered as a stationary distinction of the genome. Phenotypic and genetic plasticity are interrelated via plasticity of gene regulation by intrinsic networks with non-linear dynamics. In the "evo-devo" (evolution - development) perspective of plasticity epigenetic dynamics must be essential, and thus, plasticity may also be considered to be a process. Closely related to plasticity is diversity and this is of enormous concern in conservation. As a feature of space, ecological niches are shaped by spatiotemporal-functional dynamics of plasticity. Plasticity of plants in growth and development is essential for their occupation of space. There is a dual plasticity, i.e. plasticity of species and plasticity of niches. Conservation of protected areas sustains space as a resource of life. Plasticity may either attenuate or accelerate speciation. In the latter case it is a source of biodiversity. The genotypes but also the epigenetic properties of DNA and histone methylation are products of evolution. With the essential role of diversity in the regulation of ecosystem functions and stability this evidently merges evolutionary and ecological aspects. We need to extend the evo-devo to an evo-devo-eco concept. It underlines the prominent role of conservation for developing ethics of respect of past evolutionary heritage and present ecological treasure. Conservation protects biodiversity as an important natural heritage of the biosphere of which man is a biological part by evolution and an operator by culture, on which man is totally dependent, and which by ethical imperative man must conserve.
\end{abstract}

Key words: Conservation, Ecophysiology, Plasticity, Plants, Phenotypes, Genotypes.

\section{Plasticity and Conservation: Setting the Scene}

Plastic is anything - mostly any material -, that is capable of being moulded. An encyclopedic dictionary says that in biology plastic means exhibiting adaptability to environmental change. However, this definition is too narrow. Plasticity includes responses to internal conditions. Most plastic is the human brain and with it the human mind. In reactions to external and internal stimuli and even with repair of some serious injuries the brain's plasticity is enormous (La Recherche 2010). One outcome of plasticity is flexibility. However, what has plasticity to do with conservation? Closely related to plasticity is diversity and this indeed is of enormous concern in conservation. The fashionable key word is "biodiversity". Plasticity may endow organisms with functional flexibility. This may then lead to functional diversity of organisms within populations or of species within larger units such as habitats or ecosystems. There is diversity of species, or floristic diversity when we talk of plants, and plasticity may support speciation as we

\footnotetext{
*Send correspondence to: Prof. Dr. Ulrich Luettge Institut fuer Botanik, Technische Universitaet Darmstadt, Schnittspahnstrasse 3-5, D-64287 Darmstadt, Germany E-mail: Luettge@bio.tu-darmstadt.de
}

shall see below. There is diversity of niches, sites, habitats and ecosystems.

Although globally there is still a very large gap between practice and basic consent it is generally accepted that diversity is important for and in need of conservation. This centers plasticity into the focus of conservation. Evidently, with this said, a note of caution is also required. Some environments are characterized by often single dominating factors of stress or "stressors". Such sites, habitats or ecosystems can be highly unique and valuable natural heritage although under extreme single factor stress there will be little biodiversity. For acclimation specialization and rigidity will be more in demand than plasticity. Illustrative examples are extreme deserts where water is the dominant stressor or Antarctic territories and high altitude alpine systems (outside the tropics) where temperature is the dominant stressor. Only a small number of species that have evolved specific traits for dealing with the specific stress will occupy such sites. Nevertheless they can be just as urgently worth protection and conservation than diversity hot spots. Conversely in the tropics it is normally multi-factor and not single-factor stress that 
characterizes the various ecosystems, including the great ecosystems of Brazil, namely its forests (mainly moist or rain forests, flood forests), its flood plains, its cerrados, its inselbergs and high altitude vegetation. Naturally, there are also unique special sites in the tropics with single factor stress. The rushes of water in rivers and water-falls with their specialized rheophytes, e.g. Podostemonaceae, come to my mind. Generally, however, multi-factor stress rather than single-factor stress is determining plant life and this requires plasticity. Thus, it is the intention of this brief essay to evaluate various aspects of plasticity and why they need to be considered in strategies of conservation.

\section{Plasticity: Phenotypes and Genotypes}

It is one of the most basic concerns of conservation to protect genotypes. The genotype comprises the complete genetic information of an organism. It is the product of evolution. Evolutionary selection produces adaptation, i.e. genetically adapted individuals. Such evolutionary adaptation is a long term process. In development during ontogeny the genotype generates a certain phenotype.

For the phenotypes we distinguish morphotypes and physiotypes. The complete set of phenotypical traits generated by a genotype in the morphological domain is the morphotype and in the physiological domain is the physiotype (Kinzel 1972, 1982). The morphotypes are structural life forms as delineated by comparative morphology and anatomy. The physiotypes are physiological life forms as delineated by comparative physiology, biochemistry and molecular biology. In ecology and physiological ecology the phenotype is always the direct receiver of environmental input. This reception of external information may require acclimation by short-term and often also reversible phenotype expression. By feed-back or feed-forward via the phenotype there will be a regulatory demand on the genotype with selective gene regulation potentially generating differently acclimated phenotypes. Thus, due to feed-back or feed-forward the phenotypes are both receivers and products of environmental input. They are generated by the genotype under the pressure of external cues. This implies that the various genotypes may be capable of generating phenotypic plasticity to a smaller or larger extent.

"Phenotypic plasticity is defined as the ability of one genotype to produce more than one phenotype when exposed to different environments" (Garland \& Kelly 2006). Individual genotypes can express numerous phenotypes (Vogt et al. 2008). In this sense we may speak of plasticity of individual organisms. Conversely, if we consider phenotypic plasticity in relation to co-occurrence of different genotypes within a population which are each adapted to a slightly different environment we have the plasticity of a population. In this case it is genetic variation which is reflected in phenotypic plasticity (Booy et al. 2000).

The individual plasticity given by one individual genotype evidently implies that plasticity is due to not only genotypic variation (in populations!) but also gene regulation (in individuals!). This involves hierarchies of genes as well as net works. We realize that phenotypic and genetic plasticity may be interrelated. Phenotypes and genotypes are integrated in common networks (Hütt \& Lüttge 2005; Lüttge 2005). Plasticity may be considered as a dynamic process rather than a fixed character. A plethora of biochemical, metabolic and physiological processes are involved in generating plasticity at the level of individual organisms. Since Darwinian selection acts on the individual it can be stated that the capacity of plasticity itself will be subject to evolutionary selection. One may ask the question if there may be particular concrete plasticity genes. Indeed, it is often argued in the life science literature that for complex inclinations including physiological and psychical diseases and aberrations of man specific genes are responsible and research is searching for them. Thus, why should there not be specific plasticity genes? With the multitude of functions involved in plasticity I very much doubt that this can be a complete and satisfactory explanation. There are no single distinct paraphernalia making up plasticity. Major traits are complexes and comprise complements of subordinate traits (Garland \& Kelly 2006). Generally genomes appear to be too small to have specific genes governing most complex complements of functionality. The more likely explanation is epigenetic regulation of gene expression.

The concept of epigenetics dates back to Johann Friedrich Blumenbach (1752-1840), and the term epigenetics then has been specified at the beginning of the 1930s by Conrad Hal Waddington (1905-1975) (Gierer 1988). It is now strongly revived by the evo-devo-concept (evolution development). For among other reasons the concept is much needed because we realize that genomes are often astonishingly small. An outstanding example is the genome of man who has 20 to 30 thousand genes compared to the 15 to 20 thousand genes of a nematode and the fly Drosophila or the 27 thousand genes of the higher plant Arabidopsis thaliana, and who shares $98.7 \%$ of his genes with the chimpanzee, i.e. differs by barely a few hundred genes from the chimpanzee. Evidently we need much more than genomics for explaining high complexity. Biology must abandon its genome centered views. This is precisely what the epigenetics concept achieves. It aims at explaining the external manifestation or overt output of genetic activity and with that also the appearance of new structures during embryonic development or ontogeny. We can consider epigenetics broadly as gene regulation with the complex and integrated functional networks of the entire developing or developed organism. The feed-back and feed-forward links (edges) between the various nodes of networks bear out non-linear dynamics which intrinsically comprise a high degree of complexity.

This also should assist us in understanding the complexity of plasticity. The expression of different phenotypes by one given genotype in the same environment demonstrates the power of epigenetics (Vogt et al. 2008). Under the influence of 
epigenetics phenotypical plasticity is part of a developmental process. There will be developmental variation (Vogt et al. 2008). Phenotypical plasticity is the target of evolutionary natural selection. Followed by genetic assimilation where a novel phenotype is genetically fixed, genetically stable populations or ecotypes will be the result (Kinzel 1982; Turesson 1992; Pigliucci et al. 2006).

Evidently, the genetics of plasticity and the evolution of plasticity are far from being explained by any specific one gene target. Epigenetic regulation involves methylation of DNA and nucleosomal histones. It is an intriguing question and remains to be understood how selection might affect evolution of methylation properties of these macromolecules. Here we witness very strong interrelations of evolution, development and ecology. We should advance towards developing an "evo-devo-eco" concept.

\section{Plasticity: Non-Linear Dynamics}

We have seen that when conservation protects genomes it also protects complexity. The complexity is maintained by plasticity. I alluded to this by the initial remark on the human brain. This is the most complex organ with high plasticity which we know in the entire biosphere. Technical examples are systems of routes for traffic or electricity lines (Watts 1999). When certain nodes and edges break down alternatives are available and the punctually perturbed system may not even show any overt symptoms.

Complexity of feedback systems becomes evident in deterministic chaos (Schuster 1995). Deterministic chaos is borne out by population dynamics. This is also an aspect of conservation when it aims at protecting populations. We may be deeply submerged into complexity if we even only consider an apparently very simplistic case of a population, $\mathrm{x}$, of a single organism with its resources, $\mathrm{r}$, although this certainly is a highly reductionist approach vis-à-vis reality in nature. The size of the population $\mathrm{x}$ after a time interval of $\mathrm{t} 1$ from the start $\mathrm{t} 0$ will be proportional to the amount of resources, $r$ :

$\mathrm{x}_{\mathrm{t} 1} \sim \mathrm{r} \cdot \mathrm{x}_{\mathrm{t} 0}$

A negative feedback is that the population will generate competition between individuals and it will produce waste and pollution. Therefore, $\mathrm{x}_{\mathrm{t} 1}$ will also be negatively related to the size at $\mathrm{t} 0$, i.e. it will be also proportional to $1-\mathrm{x}_{\mathrm{t} 0}$ :

$\mathrm{x}_{\mathrm{t} 1} \sim\left(1-\mathrm{x}_{\mathrm{t} 0}\right)$

The result is the logistic equation:

$x_{t 1}=r \cdot x_{t 0} \cdot\left(1-x_{t 0}\right)$

Robert May (1976) has studied this equation in detail and called it "simple mathematical model with very complicated dynamics". At low $\mathrm{r}, \mathrm{x}_{\mathrm{t} 1}$ increases monotonically with increasing $r$. At medium $r$ there are bifurcations first resulting in two oscillating states between two branches. After a further bifurcation on each of the two branches there are four oscillating states. We certainly recognize a certain degree of order in these oscillations. However, when $r$ increases further new branches are erratically generated even with infinitesimally small changes of $r$. The system determined by the mathematical equation (3) has moved into chaos and its performance has become increasingly unpredictable.

The interest of conservationists must lie at first sight in the relevance of this to population dynamics (Hastings et al. 1993). However, we can advance it if we extend the meaning of $r$ from simple resource and subsume in it any kind of effective external cues (Lüttge 2008). Then we return to very general concerns of conservation. Let us consider biodiversity. I think conservationists may argue and the view is widely accepted that in a functional and highly complex ecosystem network like that of a tropical rainforest the biodiversity is its very state of order. Even if we take "order" here only metaphorically for the oscillations obtained with equation (3) we can relate this well to our observations of biodiversity. With very high stress or low $r$ there is low diversity. Only highly specialized and stress acclimated species will survive. With very low stress or high abundances or high $r$ there is also low diversity with the monopoly of only a few robust and outcompeting species. At medium stress or medium $r$ there is the "order" of diversity. High plasticity allows a wealth of solutions of acclimation and adaptation occurring together. Grime et al. (1987) have actually demonstrated this in an experiment with a number of microcosms where they applied different degrees of stress. High diversity was given only within a rather narrow window of stress intensities allowing - for the conditions of the British Isles - a dry biomass of no less than 350 and no more than 750 g.m ${ }^{-2}$.

A further aspect of nonlinear dynamics in nature is the ordering power of stochastic noise. Is that not a paradox, the ordering power of noise? Why should it be of interest for conservation? It is our daily experience that there is noise everywhere. There is noise in all living systems and subsystems. There is noise in our brain and it has been found that a certain level of noise is important for sustaining its functions via the plasticity of neuronal connections.

For explaining the contribution of noise to the generation of overt ordered functional structures let us consider a simple mathematical geometric problem. Let us assume that there is a regular sinoidal oscillation. The inherent rhythm of the oscillation becomes only visible if the peaks of the oscillation pass a certain upper threshold. However, the peaks always remain below the threshold, and hence, there is no overt rhythm. Let us now superimpose some noise to the oscillation. If the noise is rather small nothing new shall happen. If the noise is rather high the regular oscillation will disappear in the noise. A medium degree of noise, however, will lift the peaks of the oscillation just 
above the upper threshold and now the rhythm will be seen. This is called stochastic resonance or stochastic coherence. In this way noise can establish regular structures and sustain functions. There are even medicinal applications of this phenomenon.

In conclusion of this section, we see that when conservation protects complexity with its nonlinear dynamics it also protects the beauty of life with its unlimited fantasy of creating fantastic variety. The beauty of life is maintained by plasticity.

\section{Plasticity: Acquisition of Space}

Conservation has a lot to do with space. It needs to protect sites, habitats and ecosystems which occupy space. We can consider space per se as a resource (Grams \& Lüttge 2010). Acquisition and defense of space by organisms under strong environmental abiotic stress as well as under competition, i.e. strong biotic stress, is an important facet of their ecological performance.

Plants are basically immobile. Therefore unlike animals, they cannot acquire space by moving around. Plant's plasticity in growth and development is essential for their occupation of space. With respect to partitioning of resources within the whole plant organisms, i.e. allocation and distribution of nutrients and assimilates to the various organs during growth, we may distinguish between isometry and allometry (Pretzsch 2009). In isometry all linear dimensions of the plant change proportionally to each other. In this way geometric similarity is maintained during growth and development. Shape is determined by a rigid developmental program. In allometry linear dimensions do not change proportionally. There is plasticity in the development of shape in response to environmental cues.

Allometry comprises both the internal allometric partitioning processes driven by the development of size and external factors which determine biomass allocation. Allometry can be well exemplified by considering the relationship between stem diameter and crown width of European beech (Fagus sylvatica L.) and Norway spruce (Picea abies (L.) Karst.). Crown width and with it the growing space requirement of the trees increases with increasing stem diameter. For the same increase in diameter, beech has a higher demand for growing space than spruce. There is typically more lateral crown spread in the former in comparison with the more vertical and pyramidal growth of the latter (Pretzsch 2009). This is particularly important for trees competing for space in mixed dense forest stands.

Hence, plasticity determines the occupation of space by plants. A modular concept of phenotypic plasticity in plants has been proposed by De Kroon et al. (2005). It suggests that plasticity is mainly operating at the sub individual level, i.e. plasticity is effective via the expression of modules. These authors propose that "plasticity of whole plants is a by-product of modular responses, shaped by hierarchical selection" and they even quote a very extreme view where the modular concept culminates in the caricature that " $\mathrm{A}$ tree is not a tightly integrated organism but a by-product of its parts" (Hankioja 1991, quoted by De Kroon et al. 2005). Conversely, systems biology progressively unravels highly interactive regulatory networks in development and functioning of plants. Allometry reveals coordinated plastic development of the various parts of plants. Although they are non-animated living beings we must not deny plants to be integrated organisms.

\section{Plasticity: Ecological Niches}

We may consider space per se in a rather abstract way as something that can be occupied but does not in itself provide material resources that can be utilized. Thus, "empty" space in itself can be a resource (Grams \& Lüttge 2010). This concept of space differs fundamentally from the concept of ecological niche. Traditionally niche is not considered purely as space but most importantly also implies functional aspects. Recently concepts of species niches have been extended and became more sophisticated. There are two main components (Chase \& Leibold 2003): requirements of species for their survival in their environment, and impacts of species on their environment.

It is important for conservation to realize this distinction. First, the species which one wants to protect with conservation of an environment evidently have specific requirements which conservation must sustain. Second, however, quite clearly all life is always affecting its own environment. We see this not only very directly in the feedback from individuals within populations as illustrated by the logistic equation discussed above (Equation 3) and in the most dramatic way by the consequences of the increasingly growing population of man on the biosphere of our planet of which man is a biological part. In a more subtle way we observe that any life will shape its environment so that niches will change. If species arrive and get established in "empty" space, e.g. as pioneer species on bare rocks, on open sand or gravel of deserts or on newly formed volcanic islands of oceans, their activity will create new niches. We understand that niches have very complex spatiotemporal/ functional dynamics, certainly nonlinear dynamics. Niches show plasticity. With respect to the central theme of this essay, namely the plasticity of species, it is comprehensible that the two plasticities, that of niches and that of species, must match. In other words species plasticity must bear out niche plasticity. If a species has high genotypic and phenotypic plasticity it will have a larger niche width than a species with low plasticity. The niche of the species with high plasticity may overlap with the niche of the species with low plasticity and even comprise it entirely but not vice versa, of course. I shall briefly illustrate this using two examples from tropical sites and ecosystems.

The first example is the comparison of two species, i.e. species of the shrub and tree genus Clusia. Clusia multiflora H.B.K. 
is a species obligatorily performing C3-photosynthesis (C3). Clusia minor L. is a species which can switch between C3-photosynthesis and crassulacean acid metabolism (CAM). Focus and space of this essay do not allow to explain these modes of photosynthesis in detail (see Lüttge 2007a, b). It is sufficient for understanding the example to say as much as this: In C3-photosynthesis carbon dioxide, $\mathrm{CO}_{2}$, can only be taken up and fixed in the light, i.e. during the day, with simultaneous assimilation to carbohydrate. CAM plants can also fix $\mathrm{CO}_{2}$ in the dark, i.e. during the night, and store it in the form of malic acid (nota bene: "acid metabolism") from which it can be remobilized behind closed stomata during the day and be assimilated in the light. In addition some direct $\mathrm{CO}_{2}$ fixation can also be performed by CAM plants during the day. $\mathrm{C} 3$-plants must open their stomata for $\mathrm{CO}_{2}$ uptake during the day subjecting them simultaneously to pronounced respiratory loss of water. Stomatal opening for $\mathrm{CO}_{2}$ uptake during the night is associated with much less loss of water. CAM has an enormous intrinsic flexibility of expressing night time and day time $\mathrm{CO}_{2}$ uptake. In addition the C3/CAM intermediate species $C$. minor can reversibly switch completely between the $\mathrm{C} 3$ and the CAM-mode of photosynthesis. Evidently C. minor has much more ecophysiological plasticity than C. multiflora. Observations in a secondary savanna in Venezuela have shown that C. multiflora occupies open sun exposed sites, while C. minor grows in semi-shade of a deciduous forest. However, C. minor can also intrude into the open sites of C. multiflora, where both species can be found growing side by side. Conversely, C. multiflora was not observed in the semi-deciduous forest. At first sight this appears paradox, because with CAM as a water saving mode of photosynthesis $C$. minor should be better acclimated to open exposed sites. However, plasticity and niche width explain the distribution of both species. With acclimation but low adaptability the low-plasticity species C. multiflora is restricted to its smaller niche, the open sites. With high adaptability the high-plasticity species $C$. minor has a much larger niche width, comprising both the space of the forest and that of the open savanna (Lüttge 2007b).

The second example is the comparison of two ecosystems, i.e. the Atlantic rainforest and the coastal restingas of Brazil. The Atlantic rainforest is an old ecosystem. Tropical rainforests are characterized as multi-factor stress environments (Lüttge 2010). This implies that there is a particularly large variety and plasticity of niches. This in turn supports speciation as we shall consider a bit more in the following section of this essay. Hence, conditions and time have allowed speciation to occur in the Atlantic rainforest. Indeed it is rich of species including many endemic species. Conversely, the restingas are young ecosystems (Scarano 2002; Scarano et al. 2005). They stand on quaternary terrains, i.e. sandy coastal, plains (Martin et al. 1993, Scarano et al. 1997). Along the coastline of Rio de Janeiro the quaternary sandy deposits and dunes date mostly from the Holocene, having been established and re-established from 5,000 to 3,000 BP, but further north under the influence of the Paraiba do Sul river in some areas marine sandy deposits date from the Pleistocene (120,000 year BP) and remained acquiring their final shape after a series of invasions and regressions of the sea during the Holocene (Martin et al. 1993). The plant species we find in the young restingas to a large extent were coming from the old Atlantic rainforest. Approximately $80 \%$ of the species occurring in the restingas of the State of Rio de Janeiro are also found in montane rainforests (Araujo 2000). Plasticity of the rainforest species must have been important for their successful migration from the multi-factor stress environment of the rainforest to the more extreme and seasonal conditions of the restinga habitats (Scarano 2002). In other words, with high plasticity the newly arrived species in the restingas had large niche widths. However, more speciation obviously did not occur. There are hardly any endemic species in the restingas (Rizzini 1979, Araujo 2000).

The two examples, i.e. that of two species and that of two ecosystems, are from very different scales. Evidently plasticity occurs at the individual level but then has implications at higher hierarchical levels, such as species and ecosystems. The relevance for conservation at the different scalar levels appears similar. The performance of the two Clusia species with different degrees of plasticity and niche width is important in attempts of reforestation of the secondary savanna, which has in fact been initiated at the respective site in Venezuela but unfortunately was abandoned due to lack of dedicated manpower. The plasticity and niche width of Atlantic rainforest species allowing them to conquer the young restinga habitat and to create a new ecosystem with new niches there underlines the uniqueness of both Atlantic rainforest and restinga and their perplexing interrelations. In different ways as explained, plasticity affects them both. Both are most remarkable and wonderful natural heritage of Brazil with the highest priority for conservation.

\section{Plasticity and Speciation}

Species diversity is the product of speciation. There is a controversy of whether plasticity accelerates or attenuates speciation. Various genotypes may be capable of generating phenotypic plasticity to a smaller or larger extent. On this background it can indeed be debated whether plasticity may support development of new species diversity and evolutionary selection of new genotypes.

A key question is if plasticity is adaptive or not. This may be different from case to case. In any way, it is evident that plasticity may be associated with high costs in terms of resources of a plant. By this way plasticity may reduce fitness (van Kleunen \& Fischer 2005). However, this also depends on how we define and especially how we quantify fitness. This is a difficult problem and much more complex than measuring sexual reproduction and seed production (Lüttge \& Scarano 2007). Plasticity may also hinder speciation by stabilizing genotypes. Flexible 
adaptations by plasticity could protect given genotypes from selection under environmental pressure.

On the other hand plasticity may enhance speciation by allowing large ecological amplitudes (Grime et al. 1986; West-Eberhard 1986, 1989, 2003; Solbrig 1994; Lüttge 1995a,b, 2000, 2005; Gehrig et al. 2001; Lüttge \& Scarano 2004). Thus, plastic variation of phenotypes generates biodiversity. Ecological amplitudes may separate populations with reduced sets of genotypes which are specially adapted to particular sites. This may lead to new genetically stable populations which we call ecotypes (Turesson 1992; Kinzel 1982; De Jong et al. 2005). Then adaptive radiation and segregation may lead to speciation in the path of the wanderings of populations in the space of genotypes so that the development of phenotypes from genotypes is the real origin of complexity in biology (Schuster 1998).

Important opportunities to witness the traces of speciation are given on oceanic islands of recent volcanic origin such as the islands of Hawaii or of the Galápagos archipelago. The Galápagos islands are about 4 million years old. A comparison of three cactus genera, namely Opuntia, Brachycereus and Jasminocereus (all of them CAM-species), of these islands is most interesting (McMullen 1999). There are 6 species of Opuntia which together with their varieties make 14 endemic members of the genus occurring on different islands of the archipelago. Unfortunately there do not appear to be any ecophysiological studies so that we have no information about plasticity. Evidently, however, speciation must be quite active in this genus. By contrast, in another endemic cactus genus Brachycereus there is only one species, Brachycereus nesioticus (K.Schum.) Backbg., the so called lava cactus. It occurs on five islands and shows very little variability. No trends towards speciation are indicated. This endemic stem succulent cactus, grows directly on completely sun exposed and highly irradiance-absorbent black surfaces of lava fields and may be so very specifically acclimated to the extreme stress of its site that selection would immediately eliminate any variations. The third example Jasminocereus also expresses only one species on the islands, i.e. Jasminocereus thoursaii (Weber) Backbg. This species, however, represents an intermediate case as it is very variable and occurs with three varieties. It appears to be in an early stage of differentiation. Studies of the ecophysiological performance and expression of plasticity in these cacti might promise important insights into the relation between plasticity and speciation.

\section{Conclusions}

Plasticity is a feature of all living organisms including man. Degrees of plasticity may vary. There may be low plasticity and high rigidity or high plasticity and low rigidity. Plasticity is a complex trait of organisms but it does not materialise in distinct paraphernalia. It is a quality expressing spatiotemporal and functional nonlinear dynamics. Therefore plasticity may even be considered as a process. Summarizing the relevance of plasticity for conservation we may distil two central roles of plasticity from this essay:

First, it is the role of plasticity in shaping ecological niches, which is essential in the acquisition and defense of the resource space by life. Areas protected by conservation are the space of life. Man is endowed with a particularly high plasticity. By evolution man is biologically part of the biosphere on which he depends. By culture man also is operator on the biosphere. Second, it is the role plasticity can play in speciation creating biodiversity. Areas protected by conservation are the holding of biodiversity.

\section{References}

Araujo DSD, 2000. Análise florística e fitogeografíca das restingas do estado do Rio de Janeiro. [D.Sc.Thesis]. Rio de Janeiro: Universidae Federal do Rio de Janeiro.

Booy $\mathrm{G}$ et al., 2000. Genetic diversity and the survival of populations. Plant Biology, 2:379-395.

Chase M \& Leibold MA, 2003. Ecological niches. Chicago: The University of Chicago Press.

De Jong G, 2005. Evolution of phenotypic plasticity: patterns of plasticity and the emergence of ecotypes. New Phytologist, 166:101-118.

De Kroon $\mathrm{H}$ et al., 2005. Constraints on the evolution of adaptive phenotypic plasticity in plants. New Phytologist, 166:49-60.

Garland T \& Kelly SA, 2006. Phenotypic plasticity and experimental evolution. Journal of Experimental Biology, 209:2344-2361.

Gehrig H et al., 2001. Molecular phylogeny of the genus Kalanchoë (Crassulaceae) inferred from nucleotide sequences of the IST-1 and IST-2 regions. Plant Science, 160:827-835.

Gierer A, 1998. Im Spiegel der Natur erkennen wir uns selbst. Wissenschaft und Menschenbild. Reinbeck: Rowohlt.

Grams TEE \& Lüttge U, 2010. Space as a resource. Progress in Botany, 72:349-370.

Grime JP et al., 1987. Floristic diversity in a model system using experimental microcosms. Nature, 328:420-422.

Grime JP, Crick JC \& Rincon JE, 1986. The ecological significance of plasticity. In: Jennings DH and Trewawas AJ (Ed.). Plasticity in plants. Cambridge: Cambridge University Press. p. 5-29.

Hankioja E, 1991. The influence of grazing on the evolution, morphology and physiology of plants as modular organisms. Philosophical Transactions of the Royal Society B: Biological Sciences, 333:241-247.

Hastings A et al., 1993. Chaos in ecology: is mother nature a strange attractor? Annual Review of Ecology \& Systematics, 24:1-33.

Hütt M-T \& Lüttge U, 2005. Network dynamics in plant biology: current progress in historical perspective. Progress in Botany, 66:277-310. 
Kinzel H, 1972. Biochemische Pflanzenökologie. Schriften des Vereins zur Verleihung naturwissenschaftlicher Kenntnisse in Wien, 112:77-98.

Kinzel H, 1982. Pflanzenökologie und Mineralstoffwechsel. Stuttgart: Ulmer.

La Recherche, 2010. Le cerveau comment il se réorganise sans cesse. Les dossiers de LaRecherche, 40:2010. Special isssue.

Lüttge U, 1995a. Ecophysiological basis of the diversity of tropical plants: the example of the genus Clusia. In: Heinen HD, San José JJ \& Caballero-Arias H (Eds.). Nature and human ecology in the neotropics. Venezuela. p. 23-36. (Scientia Guaianae, 5).

Lüttge U, 1995b. Clusia: Ein Modellfall der ökophysiologischen Plastizität in einer tropischen Gattung. In: Rundgespräche der Kommission für Ökologie. Bayerische Tropenforschung - Einst und jetzt. vol. 10. München: Akademie der Wissenschaften. p. 173-186.

Lüttge U, 2000. Photosynthese-Physiotypen unter gleichen Morphotypen, Species und bei Klonen: Kann ökophysiologische Plastizität zur Entstehung von Diversität beitragen? Berichte der Reinhold-Tüxen-Gesellschaft, $12: 319-334$

Lüttge U, 2005. Genotypes - phenotypes - ecotypes: relations to crassulacean acid metabolism. Nova Acta Leopoldina, NF 92:177-193.

Lüttge U, 2007a. Photosynthesis. In: Lüttge U (Ed.). Clusia: a woody neotropical genus of remarkable plasticity and diversity. Berlin: Springer. p. 135-186. (Ecological Studies, 194).

Lüttge U, 2007b. Physiological ecology. In Lüttge U (Ed.). Clusia: a woody neotropical genus of remarkable plasticity and diversity. Berlin: Springer. p. 187-234. (Ecological Studies, 194).

Lüttge U, 2008. Physiological ecology of tropical plants. Berlin: Springer.

Lüttge U, 2010. Struggle of plants with crassulacean acid metabolism (CAM) in tropical environments under the action of dynamic networks of stressors. Aob Plants, published electronically.

Lüttge U \& Scarano FC, 2004. Ecophysiology. Revista Brasileira de Botânica, 27:1-10.

Lüttge U \& Scarano FR, 2007. Synecological comparisons sustained by ecophysiological fingerprinting of intrinsic photosynthetic capacity of plants as assessed by measurements of light response curves. Brasilian Journal of Botany, 30:355-364.

Martin L, Suguio K \& Flexor JM, 1993. As fluctuações de nível do mar durante o quaternário superior e a evolução geológica de "deltas" Brasileiros. Boletim do Instituto de Geografia da Universidade de São Paulo, Publicação Especial, 15:1-186.

May RM, 1976. Simple mathematical models with very complicated dynamics. Nature, 261:459-467.
McMullen CK, 1999. Flowering plants of the Galápagos. Ithaca, London: Cornell University Press.

Pigliucci M, Murren CJ \& Schlichting CD, 2006. Phenotypic plasticity and evolution by genetic assimilation. Journal of Experimental Biology, 209:2362-2367.

Pretzsch H, 2009. Re-evaluation of allometry: state-of-the-art and perspective regarding individuals and stands of woody plants. Progress in Botany, 71:339-369.

Rizzini CT, 1979. Tratado de Fitogeográfia do Brasil. vol. 2. São Paulo: Edusp.

Scarano FR, 2002. Structure, function and floristic relationships of plant communities in stressful habitats marginal to the Brazilian Atlantic rain forest. Annals of Botany, 90:517-524.

Scarano FR et al. 1997. Plant establishment on flooded and un-flooded patches of a fresh water swamp forest in southeastern Brazil. Journal of Tropical Ecology, 14:793-803.

Scarano FR et al. 2005. Physiological synecology of tree species in relation to geographic distribution and ecophysiological parameters at the Atlantic forest periphery in Brazil: an overview. Trees, 19:493-496.

Schuster HG, 1995. Deterministic chaos. Weinheim: Verlag Chemie.

Schuster P, 1998. Evolution in molekularer Auflösung. Berichte und Abhandlungen. Berlin-Brandenburgische Akademie der Wissenschaften: Akademie Verlag, 6:187- 215.

Solbrig OT, 1994. Plant traits and adaptive strategies: their role in ecosystem function. Berlin: Springer. p. 97-116. (Ecological Studies, 99).

Turesson G, 1922. The genotypic response of the plant species to the habitat. Hereditas, 3:211-350.

van Kleunen M \& Fischer M, 2005. Constraints on the evolution of adaptive phenotypic plasticity in plants. New Phytologist, 166:49-60.

Vogt G et al., 2008. Production of different phenotypes from the same genotype in the same environment by developmental variation. Journal of Experimental Biology, 211:510- 513.

Watts DJ, 1999. Small worlds. Princeton: Princeton University Press.

West-Eberhard MJ, 1986. Alternative adaptations, speciation, and phylogeny (a review). Proceedings of the National Academy of Sciences of the United States of America, 83:1388-1392.

West-Eberhard MJ, 1989. Phenotypic plasticity and the origins of diversity. Annual Review of Ecology \& Systematics, 20:249-278

West-Eberhard MJ, 2003. Developmental plasticity and evolution Oxford: Oxford University Press.

Received: September 2010

First Decision: October 2010

Accepted: October 2010 